7. Reprod. Fert. (1969) 20, 85-93

\title{
COMPARISON OF VAGINAL TOLERANCE TESTS OF SPERMICIDAL PREPARATIONS IN RABBITS AND MONKEYS
}

\author{
P. EGKSTEIN, MARGARET G. N. JAGKSON, \\ N. MILLMAN AND A. J. SOBRERO \\ Department of Anatomy, University of Birmingham; \\ Exeter Family Planning Clinic, Devon; \\ Ortho Research Foundation, Raritan, New Jersey; \\ and Margaret Sanger Research Bureau, New York
}

(Received 10th January 1969)

\begin{abstract}
Summary. In order to decide whether the rabbit method or the rhesus monkey test is better suited for routine vaginal tolerance tests of spermicidal preparations, combined trials employing both techniques were carried out in the two laboratories in which the tests had been developed.

A 'double-blind' experimental design was used in which three unknown, coded compounds were tested jointly in both laboratories and evaluated independently and reciprocally after transatlantic exchange of the resulting histological material. Both test methods and the scoring systems employed in the assessment of findings are described and illustrated by representative photomicrographs.

There was good agreement between both methods for two of the three preparations tested. For the third preparation, the rabbit test results were more consistent with the available clinical data than those of the monkey test.

It was concluded that the rabbit technique is more sensitive than the monkey test. Since it has several obvious practical advantages over the latter, it is proposed that the rabbit vagina test should be generally adopted as the standard method for establishing the local tolerance of new spermicidal preparations for vaginal use.
\end{abstract}

\section{INTRODUCTION}

Although the advent of oral contraceptives and modern intra-uterine devices has practically revolutionized fertility control, the conventional contraceptive preparations retain their popularity and continue to be used in many parts of the world. It is therefore important that they should be adequately tested for general acceptability and freedom from local irritation on the vagina before being marketed. It is, however, becoming increasingly difficult to find sufficient volunteers for human trials, and animal screening is the only practical way of establishing the local harmlessness of new products. 
Several animal species and sites, such as the rabbit's eye and the vagina of the bitch, rabbit and monkey (Carleton \& Florey, 1931; Baker, 1935, 1938; Holzaepfel, Warner, Buxton \& Howard, 1958) have been proposed and tested, but most of them have various practical or theoretical disadvantages. The two methods which are least open to objection and have been fully explored and documented are the rabbit vagina test (Ortho Research Foundation, Raritan, New Jersey) and the vaginal tolerance test in rhesus monkeys developed at Birmingham University (Eckstein, 1959).

Both methods have some advantages, as well as limitations such as the cost and complexity of the monkey test and the possible hypersensitivity of the rabbit method. They have, however, never been compared with each other, and it is therefore difficult to decide which should be preferred.

In order to overcome this difficulty which confronts large organizations like the International Planned Parenthood Federation (IPPF) as well as individual laboratories and workers, it was proposed, during preliminary discussions several years ago, to carry out a combined investigation in which the two techniques would be tested jointly on the same (unidentified) spermicidal preparations, and evaluated independently in both the Ortho and Birmingham laboratories. After prolonged transatlantic negotiations, a small trials group, comprising two laboratory workers (P.E. and N.M. with their technical staffs) and two clinicians (M.C.N.J. and A.J.S.), was formed, and detailed plans for the conduct and evaluation of the tests agreed between them.

\section{METHODS}

\section{Design of combined tests}

The tests were designed in as nearly identical a fashion as was practicable in the two laboratories. The basic plan was a 'double-blind' design, in which three unknown coded compounds, selected by the clinical members of the trials group, were tested more or less simultaneously at both Raritan and Birmingham. The resulting histological material was then exchanged and examined independently in the two laboratories, evaluation being carried out reciprocally and without knowledge of the treatment received by each animal or of the findings of the other group. Since only the monkey test procedure has been published (Eckstein, 1959) a concise description of both methods is given below.

Basically, they consist of introducing measured amounts of the test material daily through a lubricated catheter into the vagina of mature rabbits and cyclic rhesus monkeys for suitable periods, and determining their effects histologically on samples of vaginal mucosa obtained either at autopsy (rabbits) or by repeated vaginal biopsy (monkeys). The essential features of the respective test procedures are shown in Table 1 and the code numbers and active ingredients of the compounds used in the present series of tests are listed in Table 2.

The volumes of the tested jellies and creams $(1.0 \mathrm{ml}$ in rabbits; $1.5 \mathrm{ml}$ in monkeys; Table 1) were chosen so as to combine maximal content of active ingredients-between five and fifteen times the human dose on a bodyweight 
TABLE 1

VAGINAL TOLERANCE TESTS IN RABBITS AND MONKEYS: GENERAL DESIGN AND EXPERIMENTAL DETAILS

\begin{tabular}{|c|c|c|}
\hline & Rabbit test & Monkey test \\
\hline No. of test animals/compound & 3 or 4 & 2 \\
\hline No. of controls & 1 or $2^{*}$ & $(1) \dagger$ \\
\hline Daily dose (ml) & 1.0 & 1.5 \\
\hline Test period & $\begin{array}{c}10 \text { days } \\
\text { (Autopsy Day 11) }\end{array}$ & 60 days or 2 menstrual cycles \\
\hline Tissue examined & $\begin{array}{l}\text { Three samples from } \\
\text { lower, mid and } \\
\text { upper vagina }\end{array}$ & $\begin{array}{l}\text { Two biopsies from lower vagina } \\
\text { during follicular phase of cycle } \\
\text { (i) before test } \\
\text { (ii) at end of test }\end{array}$ \\
\hline
\end{tabular}

* Per compound or series of tests.

$\uparrow$ None essential since each animal serves as its own control.

TABLE 2

CONTRACEPTIVE PREPARATIONS TESTED

\begin{tabular}{l|c|c}
\hline No. & Code & \multicolumn{1}{c}{ Principal spermicidal ingredients } \\
\hline 1 & AVT 64/1 & $1 \%$ Glyceryl mono-ricinoleate \\
& & $1.25 \%$ p-Triisopropylphenoxypolyethoxyethanol \\
2 & AVT 64/4 & $0.15 \%$ Hexylresorcinol, B.P. \\
3 & AVT 64/5 & $5.0 \%$ Iso-octylortho-cresol 12 E.O. \\
& & $2.0 \%$ 'Carbopol 934'* \\
\hline
\end{tabular}

* Gelling agent: carboxyvinyl polymer of high mol. weight.

basis-with the largest volume that could be conveniently accommodated by the average vagina and cover most of its surface, in both species.

Tablets and vaginal suppositories can be tested in the same way after crushing or mincing and dispersing them in similar volumes of physiological saline.

\section{Test procedure and evaluation of findings}

The test compounds were administered daily (except during active menstruation in monkeys) by means of a graduated syringe and lubricated widebore rubber catheter (e.g. Jaques, 18 French G, and K-Y jelly, Johnson and Johnson). The catheter was inserted into the depth of the vagina and gently withdrawn during discharge of its contents. Control rabbits were subjected to the identical daily routine, using an empty catheter. In the monkey tests, separate controls were not essential since each animal acted as its own control. In the 'Raritan' series, a control monkey was used which had saline injected into the vagina.

Possible systemic toxic effects of the compounds and their routine administration were assessed by checks on the body weight and, in the case of monkeys, by recording menstrual cycles and carrying out occasional vaginal lavages and blood analyses (haemoglobin, haematocrit, total and differential white counts) on each animal. 
Rabbit tests. At autopsy after the tenth test dose (see Table 1), the vagina was slit open ventrally between the urethral orifice and fornices, and representative samples of the lower, middle and cervical segments were taken and fixed in Bouin's solution. After fixation, the specimens were embedded in paraffin, sectioned at 5 to $7 \mu$ and stained routinely with haematoxylin and eosin and, additionally, by the periodic acid-Schiff (PAS) reaction, with and without malt diastase digestion.

A piece of uterine horn and/or ovary was similarly processed to exclude the presence of pseudo-pregnancy.

In the present combined experiments, all rabbit samples obtained in both laboratories were processed uniformly at Raritan (Ortho Research Foundation), but sections of the monkey biopsies were prepared separately in each laboratory. Duplicate sets of slides were then exchanged between and independently evaluated by each group, as well as by the clinical team members. Representative photomicrographs were prepared from both series of sections and are included in this report.

A semi-quantitative system of scoring the rabbit slides, elaborated by one of us (N.M.), has been in use at the Ortho Research Foundation for several years and was employed in the present studies. Its four basic criteria are: epithelial ulceration; leucocytic infiltration; oedema; and vascular injection, a score of 0 to 4 ('none' to 'intense') being allotted to each of them, and compared with those in controls. A total score of between 0 and 8 is considered 'acceptable', one of 11 or over as 'unacceptable' and an intermediate one of 9 or 10 as 'marginal' (either 'acceptable' or 'unacceptable'). Photomicrographs illustrating a graded series of vaginal responses and their scores are shown in Plates 2A and $2 \mathrm{~B}$.

Monkey tests. The technique of obtaining vaginal biopsies from rhesus monkeys has been described (Eckstein, 1959). The animals are anaesthetized with intravenous pentobarbital (Nembutal, Abbots), a tiny fold of mucosa on the ventrolateral wall of the vagina, about 3 to $4 \mathrm{~cm}$ from the vulva, is picked up with forceps, cut off at its base with a long-handled knife or scissors and dropped immediately into fixative (aqueous Bouin). One control biopsy is obtained before the test and one after the end of the experimental period, usually two menstrual cycles or about 60 days (see Table 1). In the Birmingham tests a second experimental vaginal biopsy and cervical biopsies from the portio vaginalis were also obtained occasionally.

A scoring system similar to the rabbit one can also be employed for monkey biopsies, but is more difficult to apply, mainly because of the minute size and frequent fragmentation of specimens and the occasional occurrence of odd or

Direct comparison of rabbit and monkey tests. Representative sections illustrating the vaginal response of rabbits and monkeys exposed to the same test compounds. Rabbit test (autopsy)-left column. Monkey test: middle column-before treatment; right column-at end of treatment. (All $\mathrm{H} \& \mathrm{E}: \times 75$, except Fig. 2: $\times 30$.)

Group A (top row) = Controls; Figs. 1 and 3: Normal (no irritation). Group B (second row) $=$ AVT 64/1; Figs. 4 and 6: Normal (no irritation). Group $\mathrm{C}$ (third row) = AVT 64/4; Figs. 7 and 9: Normal (no irritation). Group D (fourth row) = AVT 64/5; Fig. 10: Abnormal (irritation). Fig. 12: Normal (no irritation). 
PLATE 1
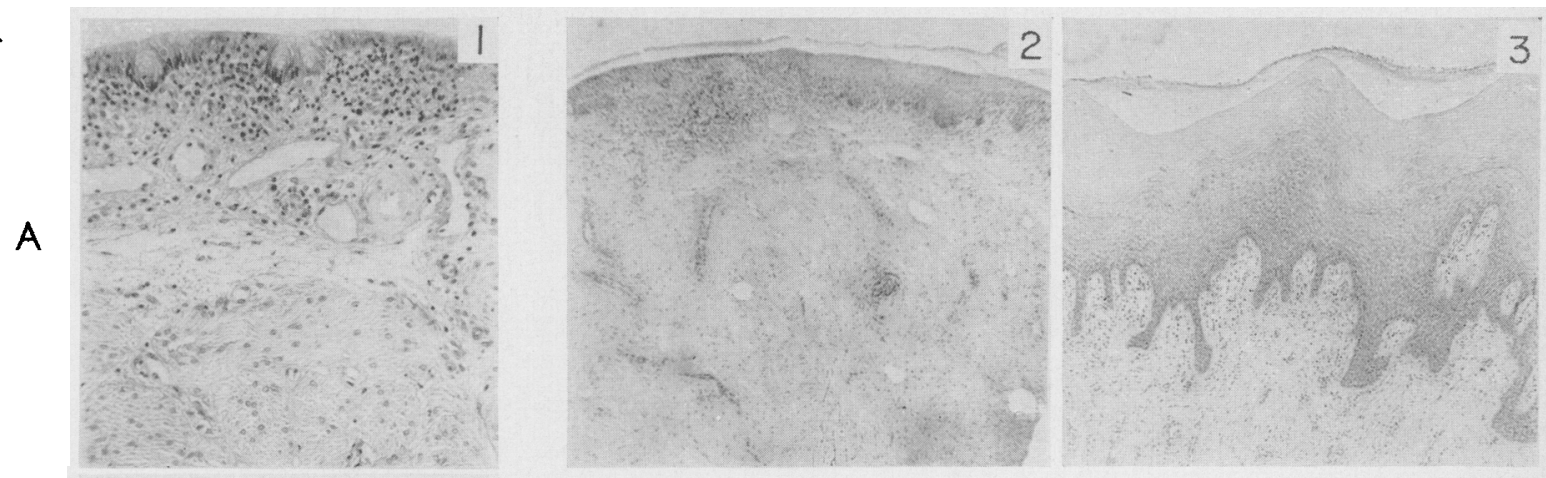

4
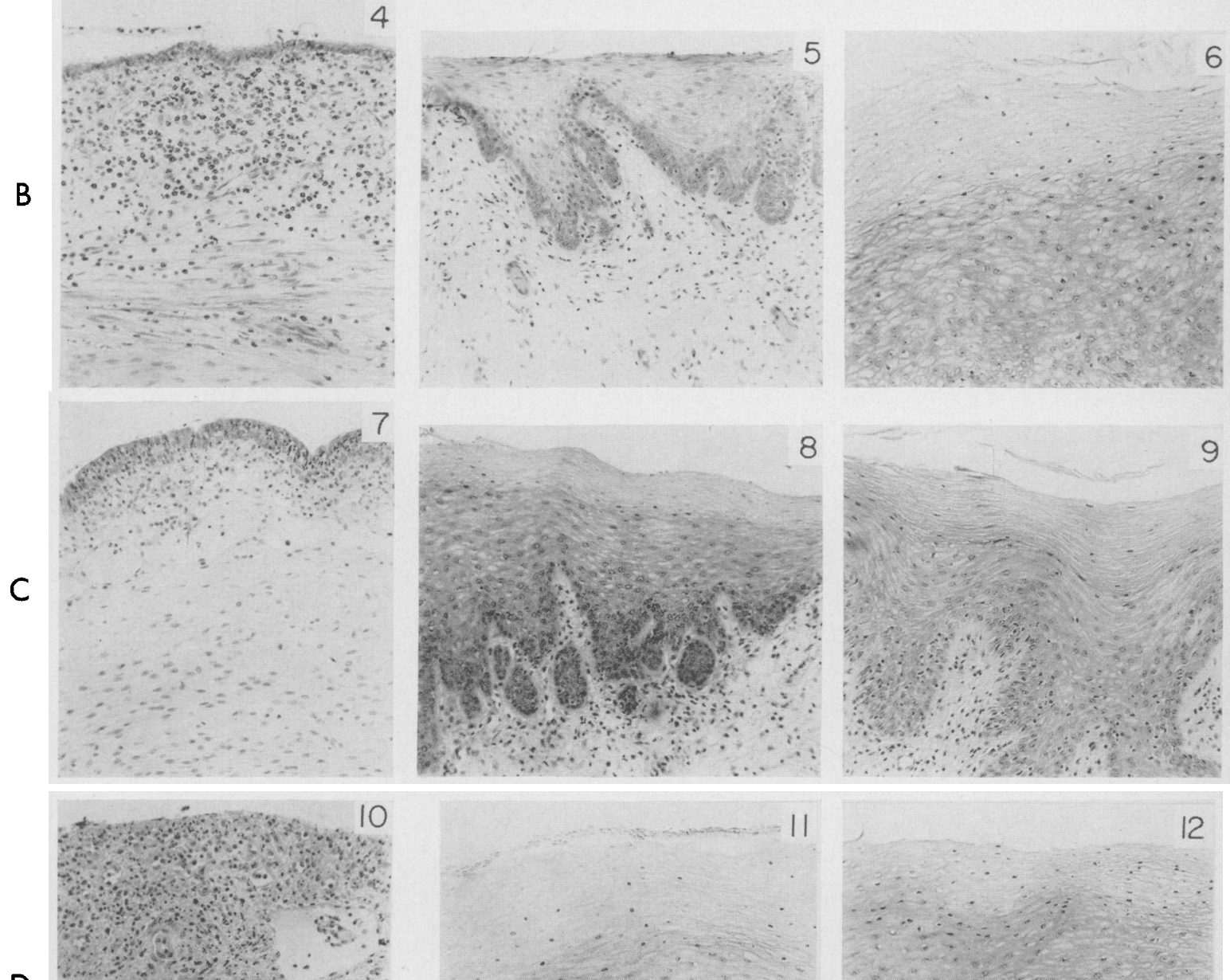

D

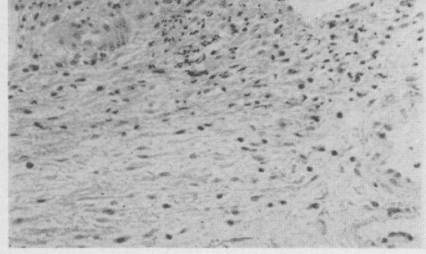

II 
PI. ITF, 2
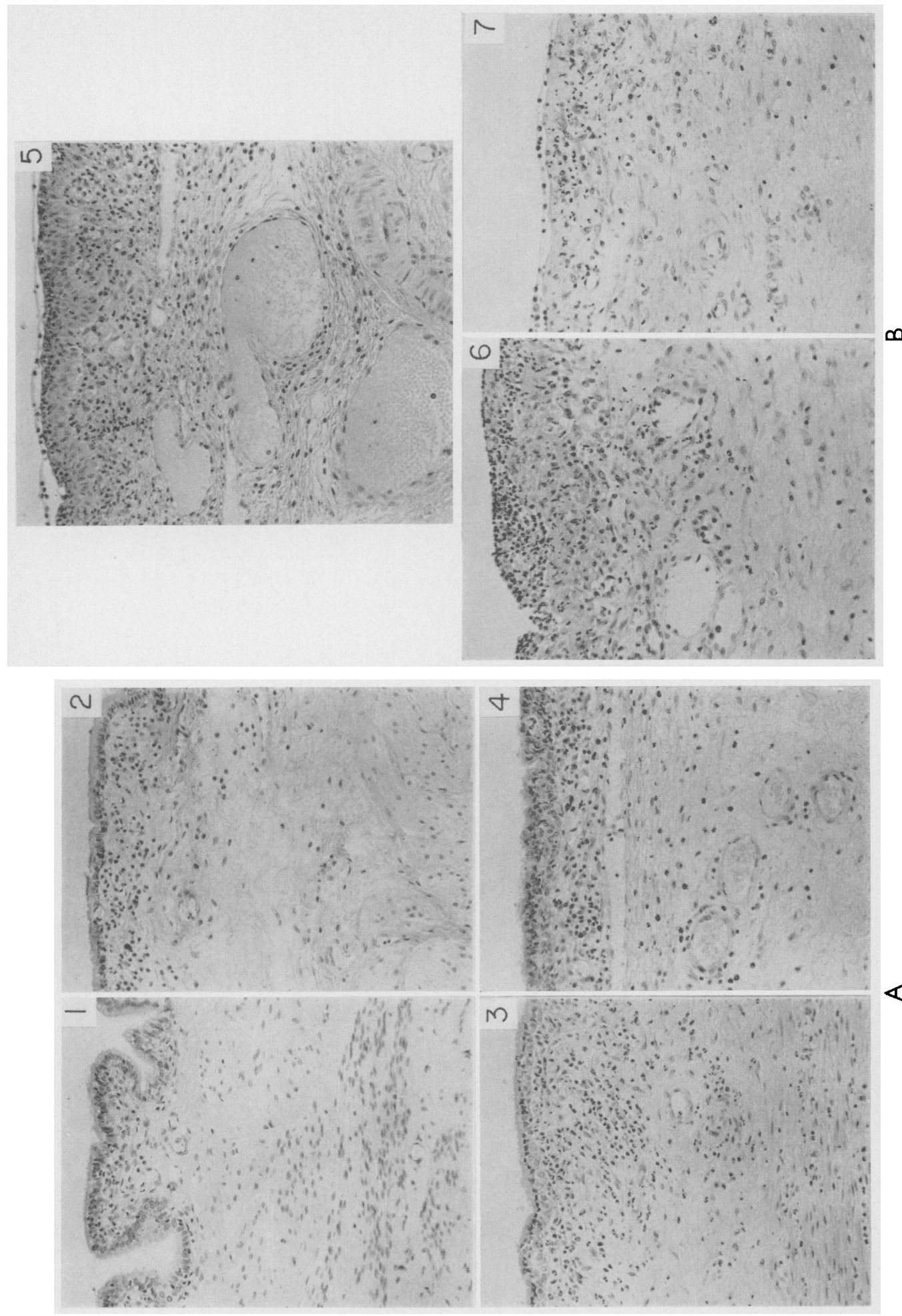

(Facing 1). 89) 
unclassifiable features such as epithelial hyperkeratosis, irregularity in either thickness, cornification or PAS-staining of the epithelium, etc. Photomicrographs of some biopsies obtained in the monkey tests are shown in Plate 1.

The findings from both the rabbit test and, as far as possible, the monkey test have been evaluated in accordance with the scoring system described above.

The assessment of clinical harmlessness (see Table 5) is based on the criteria of the Margaret Sanger Research Bureau 21-day test and the Exeter Acceptability test (Stone, 1955; IPPF Medical Handbook, 1965).

For the Margaret Sanger Research Bureau's 21-day vaginal tolerance test, twelve volunteer women use the preparation for 21 consecutive nights, starting after the end of menses. Pelvic examination and a Papanicolaou smear are made before and immediately after the trial period, as well as vaginal examinations twice weekly during the 21 days. Subjective complaints such as burning, irritation, discomfort or leakage are recorded and any evidence of vaginal or cervical irritation is noted. Not more than two women should discontinue the test because of discomfort or irritation.

In the Exeter Acceptability test (U.K.), the contraceptive preparation is issued to about 150 unselected women who are either using some type of occlusive cap or whose husbands are using a condom. The product under test should be in regular use for at least 3 months, with follow-up checks for complaints done periodically and at the end of the trial period. Of approximately 100 women remaining at the end of the trial, not more than $10 \%$ should have had to discontinue the use of the preparation because of local irritation or other complaints.

\section{RESULTS}

The most relevant findings that have emerged from this combined study and the correlations with clinical observations on the same test compounds (see above) are shown in Tables 3 to 5 and Plates 1 and 2A and B.

\section{EXPLANATION OF PLATES 2A AND B}

Selected responses to test compounds and total vaginal scores (cf. text p. 91) in the rabbit test. All H \& E, $\times 94$.

\section{A}

Fig. 1. Control: score 2 to 3 (no irritation).

Fig. 2. 64/1: score 4 to 6 (no irritation). Some stromal oedema.

FIG. 3. 64/1 : score 6 to 8 (slightly suspicious). Sub-epithelial leucocytic infiltration.

Frg. 4. 64/1: score 7 to 9 (suspicious). Leucocytic infiltration of whole mucosa; oedema and marked vascular congestion.

B

Fig. 5. 64/4: score 10 to 11 (moderate irritation). Intense vascular congestion; inflammatory exudate along lumen.

Frg. 6. 64/5: score 11 to 15 (moderate to marked irritation). Epithelium partly replaced by inflammatory exudate; vascular congestion.

FIG. 7.64/5: score 12 to 13 (moderate to marked irritation). Complete loss of epithelium; inflammatory exudate along lumen; moderate oedema and congestion. 
TABLE 3A

RABBIT TEST: RARITAN SERIES

\begin{tabular}{c|c|l|l}
\hline & & \multicolumn{2}{|c}{ Grading* } \\
\hline $\begin{array}{c}\text { Test material } \\
(\text { AVT })\end{array}$ & $\begin{array}{r}\text { Rabbit no. } \\
(1.0 \text { ml/day } \times 10)\end{array}$ & \multicolumn{1}{|c}{ Birmingham } & \multicolumn{1}{|c}{ Raritan } \\
\cline { 3 - 4 } $64 / 1$ & 1 & Acceptable & Acceptable \\
$64 / 1$ & 2 & Acceptable, marginally & Acceptable \\
$64 / 1$ & 3 & Acceptable & Acceptable \\
$64 / 4$ & 4 & Not acceptable, marginally & Acceptable \\
$64 / 4$ & 5 & Acceptable, marginally & Acceptable \\
$64 / 4$ & 6 & Acceptable, marginally & Acceptable \\
$64 / 5$ & 7 & Not acceptable & Not acceptable \\
$64 / 5$ & 8 & Not acceptable & Not acceptable \\
$64 / 5$ & 9 & Not acceptable & Acceptable, marginally \\
Nil (control) & 10 & Normal & Normal \\
\hline
\end{tabular}

* Assessed independently and reciprocally in both laboratories.

TABLE 3B

RABBIT TEST: BIRMINGHAM SERIES

\begin{tabular}{|c|c|c|c|}
\hline \multirow{2}{*}{$\begin{array}{l}\text { Test material } \\
(A V T)\end{array}$} & \multirow{2}{*}{$\begin{array}{c}\text { Rabbit no. } \\
(1 \cdot 0 \mathrm{ml} / \mathrm{day} \times 10)\end{array}$} & \multicolumn{2}{|c|}{ Grading* } \\
\hline & & Birmingham & Raritan \\
\hline $\begin{array}{l}64 / 1 \\
64 / 1 \\
64 / 1 \\
64 / 1\end{array}$ & $\begin{array}{l}1 \\
2 \\
3 \\
4\end{array}$ & $\begin{array}{l}\text { Acceptable } \\
\text { Acceptable } \\
\text { Acceptable, marginally } \\
\text { Acceptable, marginally }\end{array}$ & $\begin{array}{l}\text { Acceptable } \\
\text { Acceptable } \\
\text { Acceptable } \\
\text { Acceptable }\end{array}$ \\
\hline $\begin{array}{l}64 / 4 \\
64 / 4 \\
64 / 4\end{array}$ & $\begin{array}{l}5 \\
6 \\
7\end{array}$ & $\begin{array}{l}\text { Acceptable, marginally } \\
\text { Acceptable } \\
\text { Acceptable }\end{array}$ & $\begin{array}{l}\text { Acceptable } \\
\text { Acceptable } \\
\text { Acceptable }\end{array}$ \\
\hline $\begin{array}{l}64 / 5 \\
64 / 5 \\
64 / 5\end{array}$ & $\begin{array}{r}8 \\
9 \\
10\end{array}$ & $\begin{array}{l}\text { Not acceptable } \\
\text { Not acceptable } \\
\text { Not acceptable }\end{array}$ & $\begin{array}{l}\text { Not acceptable } \\
\text { Not acceptable } \\
\text { Not acceptable }\end{array}$ \\
\hline $\begin{array}{l}\text { Nil (Control) } \\
\text { Nil (Control) }\end{array}$ & $\begin{array}{l}11 \\
12\end{array}$ & $\begin{array}{l}\text { Normal } \\
\text { Normal }\end{array}$ & $\begin{array}{l}\text { Normal } \\
\text { Normal }\end{array}$ \\
\hline
\end{tabular}

* Assessed independently and reciprocally in both laboratories.

TABLE 4A

MONKEY TEST: RARITAN SERIES

\begin{tabular}{c|c|c|c}
\hline \multirow{2}{*}{ Test material } & & \multicolumn{2}{|c}{ Grading* } \\
\hline (AVT) & $\begin{array}{c}\text { Monkey no. } \\
\text { (daily dose } 1.5 \mathrm{ml})\end{array}$ & Birmingham & Raritan \\
\hline $64 / 1$ & 1 & Acceptable & Acceptable \\
$64 / 1$ & 3 & Acceptable & Acceptable \\
$64 / 4$ & 2 & Acceptable & Acceptable \\
$64 / 4$ & 4 & Acceptable & Acceptable \\
$64 / 5$ & 7 & Acceptable & Acceptable \\
$64 / 5$ & 11 & Acceptable & Acceptable \\
Saline (Control) & 6 & Normal & Normal \\
\hline
\end{tabular}

* Assessed independently and reciprocally in both laboratories. 
TABLE 4B

MONKEY TEST: BIRMINGHAM SERIES

\begin{tabular}{|c|c|c|c|}
\hline \multirow{2}{*}{$\begin{array}{l}\text { Test material } \\
\quad(A V T)\end{array}$} & \multirow{2}{*}{$\begin{array}{l}\text { Monkey no. (and daily } \\
\text { dose) }\end{array}$} & \multicolumn{2}{|c|}{ Grading* } \\
\hline & & Birmingham & Raritan \\
\hline $\begin{array}{l}64 / 1 \\
64 / 1\end{array}$ & $\begin{array}{l}1(1.5 \mathrm{ml}) \\
2 \dagger(1.5 \mathrm{ml})\end{array}$ & $\begin{array}{l}\text { Acceptable, marginally } \\
\text { Acceptable }\end{array}$ & $\begin{array}{l}\text { Acceptable } \\
\text { Acceptable }\end{array}$ \\
\hline $\begin{array}{l}64 / 4 \\
64 / 4\end{array}$ & $\begin{array}{l}5(1.5 \mathrm{ml}) \\
6(1.5 \mathrm{ml})\end{array}$ & $\begin{array}{l}\text { Acceptable } \\
\text { Acceptable }\end{array}$ & $\begin{array}{l}\text { Acceptable } \\
\text { Acceptable }\end{array}$ \\
\hline $64 / 5$ & $\begin{array}{l}3(1.5 \mathrm{ml} \times 30 \text { days; } \\
1.0 \mathrm{ml} \text { for next } \\
36 \text { days })\end{array}$ & Acceptable, marginally & Acceptable \\
\hline $64 / 5$ & $\begin{array}{l}4 \dagger(1.5 \mathrm{ml} \times 31 \text { days } \\
1.0 \mathrm{ml} \text { for next } \\
36 \text { days })\end{array}$ & $\begin{array}{l}\text { Acceptable, marginally; } \\
\text { irritation of cervix }\end{array}$ & Acceptable, marginally \\
\hline
\end{tabular}

* Assessed independently and reciprocally in both laboratories.

$\dagger$ Irregular cycles or amenorrhoea during test.

They can be summarized as follows:

\section{Rabbit tests}

There was good agreement between both the Raritan and Birmingham series and with the available clinical information on all three materials (AVT 64/1, $64 / 4,64 / 5$; see Tables 3 and 5 and Plate 1 , groups $A$ to $\mathbf{C}$ ).

The first two preparations yielded average total scores in the vaginal tests (see above, p. 88) of 5 to 8 or less, and were thus 'acceptable', whereas compound AVT 64/5 almost invariably gave scores of 10 or more, and hence was graded as 'unacceptable' (Table 5, Plate 1, group D and Plate 2B).

\section{Monkey tests}

The results on compounds AVT $64 / 1$ and AVT $64 / 4$ were equally acceptable, usually giving scores of 4 to 6 and only occasionally 8 to 9 . They were also

TABLE 5

VAGINAL TOLERANGE TESTS: OVERALL COMPARISONS AND GLINICAL CORRELATIONS

\begin{tabular}{|c|c|c|c|c|c|c|}
\hline \multirow{2}{*}{$\begin{array}{c}\text { Test } \\
\text { compound }\end{array}$} & \multicolumn{2}{|c|}{ Rabbit test* } & \multicolumn{2}{|c|}{ Monkey test $\dagger$} & \multirow{2}{*}{$\begin{array}{c}\text { Comparison } \\
\text { between } \\
\text { tests }\end{array}$} & \multirow{2}{*}{$\begin{array}{c}\text { Clinical } \\
\text { assessment }\end{array}$} \\
\hline & Birmingham & Raritan & Birmingham & Raritan & & \\
\hline AVT $64 / 1$ & Acceptable & Acceptable & Acceptable & Acceptable & Consistent & Acceptable \\
\hline AVT $64 / 4$ & Acceptable & $\begin{array}{l}\text { Acceptable, } \\
\text { marginally }\end{array}$ & Acceptable & Acceptable & Consistent & Acceptable $\dagger$ \\
\hline AVT $64 / 5$ & $\begin{array}{c}\text { Not } \\
\text { acceptable }\end{array}$ & $\begin{array}{c}\text { Not } \\
\text { acceptable }\end{array}$ & $\begin{array}{l}\text { Acceptable, } \\
\text { marginally }\end{array}$ & Acceptable & $\begin{array}{c}\text { Inconsistent } \\
\text { (Not accept- } \\
\text { able in rabbit } \\
\text { test; margin- } \\
\text { ally acceptable } \\
\text { in monkey test) }\end{array}$ & $\underset{\text { acceptable }}{\text { Not }}$ \\
\hline
\end{tabular}

* cf. Table 3.

+ cf. Table 4.

M.S.R.B. 21.day Test (see p. 89).

Exeter Acceptability Test (see p. 89). 
consistent, both between the Raritan and Birmingham series and on comparison with the rabbit and clinical findings. There was inconsistency, however, with regard to AVT 64/5 which, on balance, was acceptable in the monkey test, but was clearly unacceptable in the rabbit test, as well as clinically. There were also minor differences between the results obtained in both laboratories with this compound in the monkey test (see Tables 4 and 5 and Plate 1, group D).

There were no constant or significant changes in body weight or composition of the blood during the experimental period. It may be inferred that the test conditions did not impose a noticeable stress on the monkeys used in these studies.

The extra information gained from the examination of PAS-stained sections from either rabbits or monkeys was slight, and there seems no justification for including this technique in routine animal tests for vaginal tolerance of spermicidal preparations.

\section{DISGUSSION AND CONCLUSIONS}

The discrepancies in the findings on compound AVT 64/5 suggest that the rabbit method may be too exacting or the monkey test too insensitive. This question cannot be resolved without further, not necessarily conclusive, studies. It is also doubtful whether such additional tests, even if wholly unequivocal, would reveal whether the sensitivity of the rabbit vagina towards chemical spermicides resembles the sensitivity of the human vagina more closely than that of the monkey. As it is impracticable to do routine vaginal irritation trials on human volunteers, it seems safest to carry out the required animal screening tests in a species with a vaginal threshold which is lower rather than higher than that of women. Compound AVT 64/5, which was found unacceptable by the rabbit vaginal test in both laboratories and marginally acceptable or acceptable by the monkey test, was not acceptable clinically. The reported findings therefore suggest that the rabbit vaginal test, as described above, is slightly more sensitive than the monkey test and more closely reflects the likely clinical condition. Since the rabbit test is also quicker, cheaper and more easily carried out and interpreted, it must be considered preferable to the monkey test and should be generally adopted as the standard method for establishing the vaginal tolerance, or harmlessness, of new topical spermicidal preparations. It can, however, only serve as a preliminary screening method, and must always be evaluated in conjunction with clinical findings in women.

\section{ACKNOWLEDGMENTS}

We wish to record our gratitude to Dr L. E. Van Petten and to Mrs Carol Taraschi of Ortho Research Foundation, Raritan, New Jersey, for their assessment and preparation of the histological material in the 'Raritan' series of tests; and to Mr J. Browning of the Department of Anatomy, University of Birmingham, for his invaluable help in the conducting of the 'Birmingham' tests. 


\section{REFERENCES}

BAKRR, J. R. (1935) The chemical control of conception. Chapman and Hall, London.

BAKER, J. R. (1938) The production of a vaginal epithelium suitable for the testing of chemical contraceptives in the laboratory for harmful effects. F. Contracept. 3, 105.

Garleton, H. M. \& Florey, H. (1931) Birth control studies. 2. Observations on the effects of common contraceptives on the vaginal and uterine mucosa. 7. Obstet. Gynaec. Br. Emp. 38, 555.

Eckstenn, P. (1959) Harmlessness tests of chemical contraceptives in rhesus monkeys. Proc. 6th int. Conf. plann. Parent., New Delhi, p. 260. IPPF, London.

Holzaepfel, J. H., Warner, J. S., Buxton, J. A. \& Howard, J. A. (1958) Sensitivity to vaginal jellies: correlation between clinical tests and animal tests. F. Am. Pharm. Ass. (Sci. Ed.), 47, 423.

IPPF (1965) Medical handbook, 2nd edn., p. 78. Ed. R. L. Kleinman. IPPF, London.

Stone, A. (1955) Clinical tests of chemical contraceptives. Proc. 5th int. Conf. plann. Parent., Tokyo, p. 150. IPPF, London. 